\title{
The Usefulness of the Modified Frailty Index for Muscle-Invasive Bladder Cancer Patients Treated with Radical Cystectomy
}

\author{
Maarten J.H. Voskamp ${ }^{\mathrm{a}} \quad$ Marloes Vermeer $^{\mathrm{b}} \quad$ Gerd-Jan Molijn ${ }^{\mathrm{a}} \quad$ Erik B. Cornel ${ }^{\mathrm{a}}$

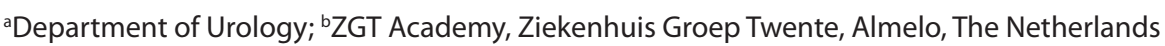

\author{
Key Words \\ Bladder cancer • Cystectomy • Frailty Index • \\ Postoperative complications
}

\begin{abstract}
Background: Radical cystectomy is still the gold standard for muscle-invasive bladder carcinoma (MIBC) treatment. In order to reduce postoperative complications, multimodality bladder-sparing therapies could be a good alternative. Studies in various malignancies have shown that the modified Frailty Index ( $\mathrm{mFI}$ ) may be more useful for identifying highrisk patients. Objectives: We investigated the possible correlation between the $\mathrm{mFI}$ in cystectomy patients with MIBC and serious complications 30 and 90 days postoperatively. Methods: Analysis of a prospective database of 109 consecutive MIBC patients who underwent a cystectomy between January 2012 and August 2017 was performed. The $\mathrm{mFI}$ was added retrospectively. Differences between groups were tested with independent t-tests, Mann-Whitney $U$ tests, ANOVA, Kruskal-Wallis test, or Chi square tests as appropriate. Univariate and multivariate logistic regression analysis were performed to analyse the relation between the $\mathrm{mFI}$ and complications. Results: Patients with Clavien-Dindo $\geq 3$ at 30 and 90 days postoperatively had a significantly higher $\mathrm{mFI}$ compared to patients with Clavien-Dindo $<3$ : the odds ratio of the $\mathrm{mFI}$ for serious complications within 30 days was 1.5 (95\% confidence interval 1.1-2.1, $p=0.010$ ) and for 90 days was 1.5 (95\% confidence interval 1.1-2.1, $\mathrm{p}=0.008$ ).
\end{abstract}

\section{KARGER}

Fax +4161306 1234

E-Mail karger@karger.com

www.karger.com
(C) 2020 The Author(s)

Published by S. Karger AG, Basel Upen access

This article is licensed under the Creative Commons AttributionNonCommercial-NoDerivatives 4.0 International License (CC BY NC-ND) (http://www.karger.com/Services/OpenAccessLicense) Usage and distribution for commercial purposes as well as any distribution of modified material requires written permission.
Conclusions: We found an association between a high $\mathrm{mFI}$ and postoperative complications and mortality. The $\mathrm{mFl}$ is therefore useful when discussing treatment options with MIBC patients.

(c) 2020 The Author(s)

Published by S. Karger AG, Basel

\section{Introduction}

Worldwide there are 429,000 patients with bladder cancer, making it the 9th most common form of cancer for both sexes [1]. Bladder cancer is a disease that mainly occurs in elderly patients and due to the aging population in developed countries, this number is set to increase. In muscle-invasive bladder carcinoma (MIBC), radical cystectomy is still the gold standard treatment [2]. This procedure is associated with a high risk of morbidity and a mortality rate between 5.4 and $8.4 \%$ within 90 days [36]. With the aging of the population, the question is which patients do we still want to operate on and which do we want to offer a less invasive treatment. To reduce postoperative complications, multimodality bladder-sparing therapies could be a good alternative. In recent studies, patients were successfully treated with combinations of chemotherapy and radiotherapy [7]. No randomized studies have been performed to compare long-term results and complications of chemo-radiotherapy versus radical cystectomy. 
Table 1. Patient characteristics $(n=109)$

\begin{tabular}{|c|c|}
\hline & Values \\
\hline Male, n (\%) & $79(72.5)$ \\
\hline Female, n $(\%)$ & $30(27.5)$ \\
\hline Age, years & $68.8 \pm 8.5$ \\
\hline CCI & $3.4 \pm 1.6$ \\
\hline \multicolumn{2}{|l|}{ ASA, n $(\%)$} \\
\hline 1 & $12(11.0)$ \\
\hline 2 & $69(63.3)$ \\
\hline 3 & $28(25.7)$ \\
\hline 4 & $0(0)$ \\
\hline Median mFI (IQR) & $1(0.0-2.0)$ \\
\hline \multicolumn{2}{|l|}{$\mathrm{mFI}, \mathrm{n}(\%)$} \\
\hline 0 & $39(35.8)$ \\
\hline 1 & $28(25.7)$ \\
\hline 2 & $25(22.9)$ \\
\hline 3 & $8(7.3)$ \\
\hline 4 & $6(5.5)$ \\
\hline 5 & $2(1.8)$ \\
\hline 6 & $1(0.9)$ \\
\hline \multicolumn{2}{|l|}{11 items of the mFI, $\mathrm{n}(\%)$} \\
\hline Diabetes mellitus & $16(14.7)$ \\
\hline Congestive heart failure & $8(7.3)$ \\
\hline Hypertension requiring medication & $47(43.1)$ \\
\hline Transient ischemic attack or cerebrovascular accident & $16(14.7)$ \\
\hline Functional status 2 (not independent) & $0(0.0)$ \\
\hline Myocardial infarction & $6(5.5)$ \\
\hline Peripheral vascular disease or rest pain & $16(14.7)$ \\
\hline Cerebrovascular accident with neurological deficit & $2(1.8)$ \\
\hline Chronic obstructive pulmonary disease or pneumonia & $21(19.3)$ \\
\hline $\begin{array}{l}\text { Prior percutaneous coronary intervention, precordial } \\
\text { catch syndrome, or angina }\end{array}$ & $10(9.2)$ \\
\hline Impaired sensorium & $0(0.0)$ \\
\hline
\end{tabular}

Currently the choice of treatment is being made using the Charlson Comorbidity Index (CCI), but also age and the American Society of Anesthesiologists (ASA) physical status classification system are still used [2]. However, in some studies there was no relationship between these scores and the postoperative mortality and morbidity in elderly patients [8]. Searching for a new possibility to identify those patients at risk for severe complications after surgery, the Canadian Study of Health and Aging Frailty Index was introduced in 2007 [9]. As a derivative of this, the modified Frailty Index (mFI) - consisting of 11 points, proved useful for identifying high-risk patients in various malignancies [10-13]. These studies wereall based on data from the National Surgical Quality Improvement Program. This database includes a large number of patients. However, not all complications are scored and parameters such as hospital volume and experience of the surgeon are lacking. The extrapolation of these results to clinical practice therefore remains difficult.

The Usefulness of the Modified Frailty Index for MIBC Patients
Our aim was to investigate the usefulness of the mFI in a low-volume hospital in order to identify patients who are at greater risk of serious complications 30 and 90 days after cystectomy.

\section{Materials and Methods}

\section{Patients, Inclusion and Exclusion}

All patients who underwent a radical cystectomy for bladder cancer between January 2012 and August 2017 were included. These procedures were all open cystectomies and performed by the same 2 urologists. After August 2017 our clinic switched to robot-assisted cystectomies, which were not included in this study. Cystectomies for a non-oncological reason were excluded to create a homogeneous group. All patients were allowed to eat until 4 hours before surgery and followed a fast-track protocol postoperatively. Antibiotics (cefazolin and metronidazole) were provided prophylactically prior to the procedure. Postoperative anti-emetics and laxatives were prescribed as usual. In addition, patients were mobilized as quickly as possible, mostly within 12 hours. Patients were monitored the first night in the 24-hour recovery ward.

The following variables were registered in a database: age, comorbidities, ASA classification, age adjusted CCI, surgical details, pathology reports, duration of stay in the hospital, and complications. Retrospectively, the records of all patients were again analyzed to calculate the $\mathrm{mFI}$. The $\mathrm{mFI}$ consists of 11 patient characteristics. There are several, slightly different mFIs used in the literature, but we used the one described by Kim et al. [14]. Every variable is scored as 1 point. The scores range from 0 to 11 , with a score of 0 representing no frailty and a score of 11 representing the highest degree of frailty. Complications were recorded using the Clavien-Dindo (CD) classification system, grade 1-5 [15]. Both the 30- and 90-day complication rates were collected. Based on postoperative documentation and outpatient clinic visits within this period, a CD score of 1 to 5 was given. If there were multiple complications for the same patient during this period, the highest score was used for the analysis. Because grade 1 and 2 complications are common and grade 3 and higher complications, in particular affect the patient, it was decided to make a cut-off point at grade 3 and higher.

\section{Statistical Analysis}

Continuous data are reported as mean $\pm \mathrm{SD}$, or in the case of non-parametric data as a median with the interquartile range (IQR). Categorical variables are reported as a number with a corresponding percentage. Differences between groups were tested with independent t-tests, Mann-Whitney U tests, ANOVA, Kruskal-Wallis test, or Chi square tests as appropriate. Univariate and multivariate logistic regression analyses were performed to analyze the relation between the $\mathrm{mFI}$ (treated as a continuous variable) and complications (CD 0-2 vs. $\geq 3$ ). The following potential confounders were investigated $(\mathrm{p}<0.10)$ : gender, age, and ASA. $\mathrm{CCI}$ was not inspected as a potential confounder since the $\mathrm{mFI}$ and CCI have an overlap in their components and therefore, it was decided beforehand not to include CCI in the multivariate model. The area under the curve (AUC) of the receiver operating characteristic curve of both $\mathrm{mFI}$ and $\mathrm{CCI}$ (both treated as continuous 
Table 2. Surgery and postoperative course $(n=109)$

\begin{tabular}{|c|c|c|}
\hline & Values & \\
\hline Cutaneous diversion, $\mathrm{n}(\%)$ & $101(92.7)$ & \\
\hline Neo-bladder, n (\%) & $8(7.3)$ & \\
\hline Mean length of surgery, minutes & $227.4 \pm 55.4$ & \\
\hline Median length of stay (IQR), days & $13.0(10.0-16.0)$ & \\
\hline Median blood loss (IQR), ml & $450(300-750)$ & \\
\hline \multicolumn{3}{|l|}{ Pathological T stage, n (\%) } \\
\hline T0 & $12(11.0)$ & \\
\hline Tis-T1 & $20(18.3)$ & \\
\hline $\mathrm{T} 2$ & $28(25.7)$ & \\
\hline $\mathrm{T} \geq 3$ & $49(45.0)$ & \\
\hline \multicolumn{3}{|l|}{ Pathological N stage, n (\%) } \\
\hline N0 & $85(78.0)$ & \\
\hline N1 & $13(11.9)$ & \\
\hline $\mathrm{N} \geq 2$ & $11(10.1)$ & \\
\hline Positive soft tissue margins, n (\%) & $9(8.3)$ & \\
\hline \multicolumn{3}{|l|}{ Complications, n (\%) } \\
\hline Ileus & $28(25.7)$ & \\
\hline Urinary tract infection & $15(13.8)$ & \\
\hline Bowel injury & $2(1.8)$ & \\
\hline Fascial dehiscence & $8(7.3)$ & \\
\hline Pulmonary & $9(8.3)$ & \\
\hline Cardiac & $15(13.8)$ & \\
\hline Renal dysfunction & $7(6.4)$ & \\
\hline Delirium & $8(7.3)$ & \\
\hline CD classification, $\mathrm{n}(\%)$ & 30-Day & 90-Day \\
\hline None & 41 (37.6) & $38(34.9)$ \\
\hline Grade 1 & $9(8.3)$ & $8(7.3)$ \\
\hline Grade 2 & $31(28.4)$ & $30(27.5)$ \\
\hline Grade 3 & $15(13.8)$ & $19(17.4)$ \\
\hline Grade 4 & $11(10.1)$ & $10(9.2)$ \\
\hline Grade 5 & $2(1.8)$ & $4(3.7)$ \\
\hline
\end{tabular}

variables) was calculated. The Spearman correlation coefficient was calculated to measure the strength of association between $\mathrm{mFI}$ and $\mathrm{CCI}$

To determine a cut-off point for patients who are at risk for serious complications, a comparison of $\mathrm{mFI}$ groups was made: 0 versus 1 or higher, $0-1$ versus 2 or higher, and $0-2$ versus 3 or higher. In addition, a cut-off $\mathrm{mFI} \geq 2$ was chosen as it was previously set by Chappidi et al. [10]. We named the group of $\mathrm{mFI}<2$ 'low risk' and $\mathrm{mFI} \geq 2$ 'high risk'. Statistical analysis were performed using SPSS version 24 (IBM SPSS Statistics for Windows, Armonk, NY: IBM Corp.). Statistical significance was set at $\mathrm{p}<0.05$.

\section{Results}

\section{Baseline Characteristics}

In our study period, $109 \mathrm{MIBC}$ patients underwent a radical cystectomy with creation of a cutaneous diversion or neo-bladder. Of these patients $79(72.5 \%)$ were male and age was $68.8 \pm 8.5$ years. CCI was $3.4 \pm 1.6$.
Twelve patients (11.0\%) had ASA 1, 69 patients $(63.3 \%)$ ASA 2, 28 patients $(25.7 \%$ ) ASA 3, and there were no ASA 4 patients. The presence of the 11 items of the $\mathrm{mFI}$ are listed in table 1 . Of all patients, $39(35.8 \%)$ had a $\mathrm{mFI}$ of $0,28(25.7 \%)$ had a score of $1,25(22.9 \%)$ had a score of 2 , and $17(15.5 \%)$ had a score of $\geq 3$.

\section{Surgery and Postoperative Course}

Of the 109 patients, $68(62.4 \%)$ had a postoperative complication within 30 days and 28 of them $(41.2 \%)$ had a $C D \geq 3$. Within 90 days, 71 patients $(65.1 \%)$ had a postoperative complication, of which $33(46.5 \%)$ had a $C D \geq$ 3 . Surgical details and the postoperative course including complications are presented in table 2 . The most common complication was ileus $(\mathrm{n}=28,25.7 \%)$, followed by urinary tract infection $(\mathrm{n}=15,13.8 \%)$, and cardiac problems $(\mathrm{n}=15,13.8 \%)$.

\section{$m F I$}

Patients with $C D \geq 3$ had a significantly higher $\mathrm{mFI}$ 30 days postoperatively compared to patients with $\mathrm{CD}<$ 3: the median (IQR) $\mathrm{mFI}$ of the patients with $\mathrm{CD} \geq 3$ was $1.5(1.0-2.0)$ and of the patients with $\mathrm{CD}<3$ it was 1.0 $(0.0-2.0)(\mathrm{p}=0.007)$. The odds ratio (OR) of the $\mathrm{mFI}$ for serious complications was 1.5 [95\% confidence interval (CI) $1.1-2.1, \mathrm{p}=0.010]$. After 90 days, we found the same results: patients with $\mathrm{CD} \geq 3$ had a significantly higher $\mathrm{mFI}$ compared to patients with $\mathrm{CD}<3$ : the median (IQR) $\mathrm{mFI}$ of patients with $\mathrm{CD} \geq 3$ was 1.85 (1.0 2.5 ) and of patients with $\mathrm{CD}<3$ it was $1.0(0.0-2.0)$ (p $=0.007)$. The OR of the $\mathrm{mFI}$ for serious complications was 1.5 (95\% CI 1.1-2.1, p = 0.008). For both 30 and 90 days, age and gender were not confounders for the relation between the $\mathrm{mFI}$ and the $\mathrm{CD}$ groups. ASA was a potential confounder: ASA was related $(p<0.10)$ with the $\mathrm{mFI}$ and with $\mathrm{CD}$. However, due to an insufficient sample size ASA was not entered into the multivariate model. The receiver operating characteristic curve of the prediction model showed an AUC of 0.66 (95\%CI 0.560.77 ) for complications after 30 days and an AUC of 0.66 (95\% CI 0.55-0.76) after 90 days (both $\mathrm{p}=0.010)$. No differences in CCI were found between the the $\mathrm{CD}<3$ and $C D \geq 3$ groups after 30 and 90 days: $3.3 \pm 1.6$ vs. 3.8 $\pm 1.5(\mathrm{p}=0.096)$, and $3.3 \pm 1.6$ vs. $3.7 \pm 1.6(\mathrm{p}=0.147)$ respectively. A moderate positive correlation was found between the mFI and CCI $(\rho=0.68, p<0.001)$.

\section{Cut-Off}

A cut-off point for the mFI to classify patients at risk for serious complications after surgery could not be es- 
Table 3. 90-Day complications and mortality $(n=109)$

\begin{tabular}{lccc}
\hline & $\mathrm{mFI}<2(\mathrm{n}=67)$ & $\mathrm{mFI} \geq 2(\mathrm{n}=42)$ & $\mathrm{p}$ \\
\hline CD: all grades, $\mathrm{n}(\%)$ & $40(59.7)$ & $31(73.8)$ & 0.133 \\
CD: grade 3 or higher, $\mathrm{n}(\%)$ & $17(25.4)$ & $16(38.1)$ & 0.159 \\
Mortality, $\mathrm{n}(\%)$ & $0(0)$ & $4(9.5)$ & 0.020 \\
\hline
\end{tabular}

tablished: no value was found above which there were significantly more complications (data not shown). The cut-off point was set at $\geq 2$ as previously reported in the literature, which was also the median mFI score in the study population (median: 1.0). When setting the cut-off point at $\geq 2,42$ out of 109 patients $(38.5 \%)$ were left in the 'high risk' group. After 30 days, 30 out of 42 patients $(71.4 \%)$ in the 'high risk' group had a complication versus 38 out of $67(56.7 \%)$ in the 'low risk' group $(\mathrm{p}=0.123)$. There were noticeably more cardiopulmonary complications in the 'high risk' group: 18 out of 42 (42.9\%) versus 6 out of 67 (9.0\%) in the 'low risk' group. When we only took serious complications into account ( $\mathrm{CD} \geq 3), 14$ out of $42(33.3 \%)$ in the 'high risk' and 14 out of 67 (20.9\%) in the 'low risk' had an event $(\mathrm{p}=0.148)$. After 90 days we found almost the same results (table 3 ). We did, however, find a significant difference in mortality. After 30 days, 2 patients $(4.8 \%)$ died in the 'high risk' group and after 90 days it was 4 patients $(9.5 \%)$ versus 0 patient in the 'low risk' group $(\mathrm{p}=0.020)$.

\section{Discussion}

With the increasing age of our MIBC population and new excellent treatment modalities, clinicians and especially urologists are looking for new ways to choose the right therapy for their patients $[7,16]$. We believe that these choices can no longer be made based solely on a clinical view. Objective methods are of the utmost importance in helping both clinician and patient decide which treatment will be the best option for the patient. Traditionally, the CCI is a tool used to make a preoperative risk assessment, which is also advised by the European Urology Association guideline on MIBC [2]. The CCI is largely based on the chronological age of the patient. There are indications, however, that a biological age is more important than the chronological age. The occurrence of comorbidity will increase with the age of the patient, but this varies considerably per person. A study of Mitnitski et al. [17] showed that biological age was significantly more strongly associated with death than chronological age. This may also explain why the CCI in smaller cohorts is not related to poorer outcomes. A recent study of Atallah et al. [8] showed that there was no relationship between a high CCI and the incidence of morbidity and mortality in patients aged 75 years and older undergoing a cystectomy. In contrast to the CCI, the Canadian Study of Health and Aging Frailty Index and its derivative, the $\mathrm{mFI}$, is not based on chronological age. In the present study, the CCI was not related to serious complications after 30 and 90 days. Furthermore, the $\mathrm{mFI}$ moderately correlated with the CCI.

In the literature many frailty indexes were proposed $[9,14,18]$. For colectomy patients, the mFI was successfully used recently in discriminating those patients at risk for severe complications and mortality [12]. Patients with a high $\mathrm{mFI}$ were more likely to be discharged to non -home care [19]. Lascano et al. [13] validated the $\mathrm{mFI}$ for urological malignancies. In a cohort of 2,679 patients, Chappidi et al. [10] found 30 days after a cystectomy a higher rate of $\mathrm{CD}$ grade 4 or 5 complications and a higher overall mortality rate in patients with an $\mathrm{mFI} \geq 2$. As we also found it relevant to prevent grade 3 complications, we included these in our analysis. With this broader definition of serious complications, we were also able to prove a relation between the $\mathrm{mFI}$ and the occurrence of serious complications $(C D \geq 3)$ within 30 and 90 days of cystectomy, even in a low-volume hospital. Patients with a $C D \geq 3$ after 30 and 90 days had a significantly higher $\mathrm{mFI}$ at baseline than patients with a $\mathrm{CD}<3$.

However, there were major differences with Chappidi et al. [10]. In the National Surgical Quality Improvement Program database used by Chappidi et al. [10] gastrointestinal complications were not recorded. We think that registering these kinds of complications after a cystectomy is actually essential. In our study we found gastrointestinal complications that significantly contributed to our total complication rate in $25.7 \%$ of patients. Second, their follow-up was limited to 30 days postoperatively. 
The 90-day period captures mortality from multiple causes and is therefore more valuable when providing information to patients before surgery [20]. In our study we observed a difference in mortality between 30 and 90 days follow-up. After 30 days, 2 patients from the 'high risk' group died and after 90 days this doubled to 4 patients. Within such a small group, this doubling is a number to take into account. Finally, Chappidi et al. [10] used a database where no information was available concerning hospital volume for cystectomies, type of urinary diversion, experience of the urologists, and whether the patient underwent neoadjuvant chemotherapy. In contrast, our population was homogenous and all surgery were performed by two experienced urologists together. Patients followed the same pre- and post-operative protocol and similar follow-up.

When using risk scores, it is important to determine a cut-off value in order to classify patients at risk. Due to an insufficient sample size, no cut-off value could be set in our study. Chappidi et al. [10] set the cut-off value of the $\mathrm{mFI}$ to 2 or higher. When this cut-off was applied to our data, no significant difference was seen in the rate of serious complications, except for mortality. This could be due to the small group of patients included in this study. However, only having a cut-off value is not enough since a choice for therapy cannot be made solely on the basis of this. In practice, the conversation between patient and urologist continues to be vitally important.

There are limitations in our study. First of all, we took $\mathrm{CD}$ grade 3 or higher as an endpoint. As mentioned before, we also considered a grade 3 complication to be a serious complication that should be prevented. As other endpoints have been chosen in the literature (grade 4 or higher), it is difficult to compare our results with these studies. In addition, as previously mentioned, the sample size was not sufficient to set a cut-off point for identifying high-risk patients.

In our study we just used clinical endpoints and did not measure the patient's quality of life because we used partly prospectively and partly retrospectively collected data. It would be interesting to prospectively collect data from this vulnerable patient population when the diagnosis of MIBC is set. Moreover, it would be valuable to measure the quality of life after radical cystectomy and to include this item in the decision tree as set by guidelines. When a decision is made for various treatment modalities, risk scores could then be taken into account. If these patients could then be tracked prospectively during the various treatments, both surgical and non-surgical, the actual usefulness of risk scores could be revealed.

\section{Conclusion}

We found a relationship between the $\mathrm{mFI}$ and the occurrence of serious complications within 30 and 90 days of cystectomy in patients with MIBC. In our cohort we could not define a cut-off value for the mFI. However, it seemed that patients with a $\mathrm{mFI} \geq 2$ are more likely to die within 90 days of surgery. The mFI appears to be a useful tool for discussing treatment options with MIBC patients. Further research into the value of the risk scores is required to confirm its potential.

\section{References}

1 Ferlay J, Soerjomataram I, Dikshit R, Eser S, Mathers C, Rebelo M, Parkin DM, Forman D, Bray F: Cancer incidence and mortality worldwide: sources, methods and major patterns in GLOBOCAN 2012. Int J Cancer 2015;136:E359-E386.

2 Witjes JA, Compérat E, Cowan NC, De Santis M, Gakis G, Lebret T, Ribal MJ, Sherif A: Guidelines on muscle-invasive and metastatic bladder cancer. Guidelines 2014. https:// uroweb.org/individual-guidelines/oncology-guidelines/.

>3 Porter MP, Gore JL, Wright JL: Hospital volume and 90-day mortality risk after radical cystectomy: a population-based cohort study. World J Urol 2011;29:73-77.
4 Hautmann RE, De Petriconi RC, Pfeiffer C, Volkmer BG: Radical cystectomy for urothelial carcinoma of the bladder without neoadjuvant or adjuvant therapy: long-term results in 1100 patients. Eur Urol 2012;61:1039-1047.

-5 Stein JP, Lieskovsky G, Cote R, Groshen S, Feng AC, Boyd S, Skinner E, Bochner B, Thangathurai D, Mikhail M, Raghavan D, Skinner DG: Radical cystectomy in the treatment of invasive bladder cancer: long-term results in 1,054 patients. J Clin Oncol 2001; 19:666-675.

-6 Nielsen ME, Mallin K, Weaver MA, Palis B, Stewart A, Winchester DP, Milowsky MI: Association of hospital volume with conditional 90-day mortality after cystectomy: an analysis of the National Cancer Data Base. BJU Int 2014;114:46-55.
7 Chung PW, Bristow RG, Milosevic MF, Yi QL, Jewett MA, Warde PR, Catton CN, McLean M, Moore M, Tannock IF, Gospodarowicz MK: Long-term outcome of radiation-based conservation therapy for invasive bladder cancer. Urol Oncol 2007;25:303-309.

-8 Atallah F, Letocart P, Malavaud B, Ahmad M, Mazerolles M, Minville V: Can we predict morbidity and mortality of patients aged 75 years and older undergoing cystectomy? J Frailty Aging 2017;6:72-75.

-9 Song X, MacKnight C, Latta R, Mitnitski $A B$, Rockwood K: Frailty and survival of rural and urban seniors: results from the Canadian Study of Health and Aging. Aging Clin Exp Res 2007;19:145-153. 
10 Chappidi MR, Kates M, Patel HD, Tosoian JJ, Kaye DR, Sopko NA, Lascano D, Liu JJ, McKiernan J, Bivalacqua TJ: Frailty as a marker of adverse outcomes in patients with bladder cancer undergoing radical cystectomy. Urol Oncol 2016;34:256.e1-e6.

11 Farhat JS, Velanovich V, Falvo AJ, Horst HM, Swartz A, Patton JH Jr, Rubinfeld IS: Are the frail destined to fail? Frailty index as predictor of surgical morbidity and mortality in the elderly. J Trauma Acute Care Surg 2012;72: 1526-1531.

12 Obeid NM, Azuh O, Reddy S, Webb S, Reickert C, Velanovich V, Horst HM, Rubinfeld I: Predictors of critical care-related complications in colectomy patients using the National Surgical Quality Improvement Program: exploring frailty and aggressive laparoscopic approaches. J Trauma Acute Care Surg 2012;72: 878-883.
13 Lascano D, Pak JS, Kates M, Finkelstein JB, Silva M, Hagen E, RoyChoudhury A, Bivalacqua TJ, DeCastro GJ, Benson MC, McKiernan JM: Validation of a frailty index in patients undergoing curative surgery for urologic malignancy and comparison with other risk stratification tools. Urol Oncol 2015;33: 426.e1-e12.

14 Kim S, Brooks AK, Groban L: Preoperative assessment of the older surgical patient: honing in on geriatric syndromes. Clin Interv Aging 2015;10:13-27.

15 Dindo D, Demartines N, Clavien PA: Classification of surgical complications: a new proposal with evaluation in a cohort of $6336 \mathrm{pa}-$ tients and results of a survey. Ann Surg 2004; 240:205-213.

16 Griebling TL: Geriatric Urology. New York, Springer, 2014
17 Mitnitski AB, Graham JE, Mogilner AJ, Rockwood K: Frailty, fitness and late-life mortality in relation to chronological and biological age. BMC Geriatr 2002;2:1.

18 Sathianathen NJ, Jarosek S, Lawrentschuk N, Bolton D, Konety BR: A simplified frailty index to predict outcomes after radical cystectomy. Eur Urol Focus 2019;5:658-663.

19 Pearl JA, Patil D, Filson CP, Arya S, Alemozaffar M, Master VA, Ogan K: Patient frailty and discharge disposition following radical cystectomy. Clin Genitourin Cancer 2017;15: e615-e621.

20 Damhuis RA, Wijnhoven BP, Plaisier PW, Kirkels WJ, Kranse R, van Lanschot JJ: Comparison of 30-day, 90-day and in-hospital postoperative mortality for eight different cancer types. Br J Surg 2012;99:1149-1154. 